\title{
Analisis Fungsi Keanggotaan Fuzzy Tsukamoto Dalam Menentukan Status Kesehatan Tubuh Seseorang
}

\author{
Nurul Khairina \\ Politeknik Ganesha Medan \\ Jl. Veteran No. 190 Pasar VI Manunggal \\ nurulkhairina27@gmail.com
}

\begin{abstract}
Abstrak - Fuzzy logic sering digunakan untuk menyelesaikan masalah yang dianggap memiliki pengertian yang samar. Salah satu metode fuzzy logic adalah fuzzy Tsukamoto. Fuzzy Tsukamoto menggunakan fuzzifikasi, inferensi, aplikasi masalah ke aturan dan defuzzifikasi dalam menarik sebuah kesimpulan. Metode fuzzy Tsukamoto menggunakan operasi AND (minimum) sehingga menghasilkan $\alpha_{\text {-predikat }}$ dari setiap aturan yang ada dan menghitung nilai $\mathrm{Z}$ sebagai hasil akhir yang berpengaruh pada kesimpulan. Pada penelitian ini terdapat variabel usia, suhu tubuh, dan status kesehatan yang terdiri dari kurang sehat, sehat dan tidak sehat yang akan menjadi faktor penentu dalam penarikan kesimpulan pada akhir penelitian. Dari hasil analisis kasus anak-anak yang berumur 12 tahun dan memiliki suhu tubuh $36^{\circ} \mathrm{C}$, menurut metode fuzzy Tsukamoto yang digunakan, dapat ditarik kesimpulan bahwa status kesehatan anak tersebut masuk ke dalam kategori "kurang sehat" dan tampak bahwa hasilnya mendekati fakta yang telah diasumsikan.
\end{abstract}

Kata Kunci - Fuzzy logic, Tsukamoto, kesehatan

\section{PENDAHULUAN}

Bayi dan anak-anak memiliki suhu tubuh yang lebih tinggi dari pada orang dewasa, lansia dan manula. Suhu tubuh cenderung semakin menurun saat usia manusia tersebut semakin tua. Mackowiak, Wasserman, dan Levin pernah melakukan penelitian mengukur suhu tubuh 65 pria dan 65 wanita pada tahun 1992, pada masa itu diperoleh hasil penelitian suhu tubuh bayi yang berusia antara 0-3 tahun dan anak-anak yang berusia antara 1-5 tahun memiliki suhu tubuh $37,5^{\circ} \mathrm{C}$ dan 37,0 ${ }^{\circ} \mathrm{C}$. Namun berbeda hasilnya dengan suhu tubuh orang dewasa dan manula, orang dewasa memiliki suhu tubuh $36,4^{\circ} \mathrm{C}$ sedangkan manula yang berusia diatas 70 tahun hanya memiliki suhu tubuh $36,0^{\circ} \mathrm{C}$.

Pada penelitian kali ini, penulis ingin meneliti hubungan usia dan suhu tubuh yang dimilikinya dengan menggunakan metode fuzzy Tsukamoto.

\section{TINJAUAN PUSTAKA}

\section{A. Fuzzy Logic}

Fuzzy atau yang lebih sering dikenal dengan fuzzy logic pertama kali diperkenalkan di Universitas California di Barkeley pada tahun 1965 oleh Prof. Lutfi Asker Zadeh dalam tulisannya tentang teori himpunan fuzzy.

Menurut Kusumadewi dan Purnomo, fuzzy logic adalah suatu cara yang tepat memetakan ruang input ke dalam suatu ruang ouput [5].
Fuzzy logic merupakan cara untuk mencari solusi atas permasalahan yang dianggap samar. Dalam solusinya, fuzzy logic menggunakan bahasa seperti "agak tinggi", "tinggi”, "agak panas", "panas", dan sebagainya. Ada tiga metode dalam fuzzy logic, yaitu : fuzzy Mamdani, fuzzy Sugeno dan fuzzy Tsukamoto.

Fuzzy merupakan teori himpunan, dimana himpunan fuzzy memilki derajat keanggotaan antara 0 dan 1, dan sering ditulis [0 1] dan disimbolkan dengan $\mu$. Derajat keanggotaan didalam fuzzy dinyatakan dengan fungsi keanggotaan yang digambarkan dengan kurva yang memiliki interval antara 0 dan 1 . Berikut ini salah satu contoh kurva fungsi keanggotaan trapesium :

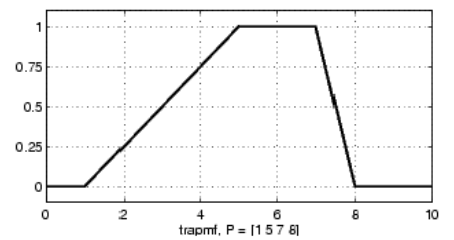

Gambar 1. Kurva Fungsi Keanggotaan Trapesium

Secara umum, fuzzy memiliki empat tahapan dalam menyelesaikan permasalahan, yaitu :

1. Fuzzifikasi :

Data masukan diubah ke dalam bentuk variabel fuzzy menggunakan fungsi keanggotaaan.

2. Inferensi :

Data masukan diproses dengan aturan-aturan (rule) yang telah ditentukan.

3. Komposisi : 
Data keluaran dari semua aturan akan digabungkan menjadi himpunan fuzzy baru.

4. Defuzzifikasi :

Data keluaran dari himpunan fuzzy akan dikonversikan kembali ke dalam bentuk bilangan dengan menggunakan fungsi keanggotaan yang telah digunakan sebelumnya.

\section{B. Fuzzy Tsukamoto}

Pada metode fuzzy Tsukamoto, proses inferensi dilakukan dengan aturan (rule) berbentuk IF-THEN dan menggunakan operasi AND, dimana akan dipilih nilai yang lebih minimum (MIN) dari dua variabel yang ada. Data keluaran dari proses inferensi dikenal dengan $\alpha$. predikat yang akan dihasilkan sebanyak aturan yang telah ditentukan.

Hasil dari perhitungan metode ini dilakukan dengan mencari nilai $\mathrm{Z}$ yang bergantung pada nilai-nilai $\alpha$. predikat sebelumnya. Berikut ini persamaan mencari nilai $\mathrm{Z}$ :

$$
\mathrm{Z}=\frac{\propto \text { pred } 1 * \mathrm{z} 1+\propto \text { pred } 2 * \mathrm{z} 2+\propto \text { pred } 3 * \mathrm{z} 3+\cdots}{\propto \text { pred } 1+\propto \text { pred } 2+\propto \text { pred } 3+\cdots}
$$

\section{1) Usia}

Usia manusia dihitung sejak manusia tersebut lahir sampai meninggal, dengan kata lain, usia adalah satuan yang mengukur keberadaan suatu makhluk itu sejak lahir sampai makhluk itu mati. Menurut Departemen Kesehatan RI tahun 2009, usia dapat dikategorikan sebagai berikut [8] :

Tabel 1. Kategori Usia Manusia

\begin{tabular}{|c|c|}
\hline \multicolumn{2}{|c|}{ Kategori Usia } \\
\hline Balita & $0-5$ \\
\hline Kanak-kanak & $5-11$ \\
\hline Remaja Awal & $12-16$ \\
\hline Remaja Akhir & $17-25$ \\
\hline Dewasa Awal & $26-35$ \\
\hline Dewasa Akhir & $36-45$ \\
\hline Lansia Awal & $46-55$ \\
\hline Lansia Akhir & $56-65$ \\
\hline Manula & 65 keatas \\
\hline
\end{tabular}

\section{2) Suhu Tubuh}

Suhu tubuh manusia dapat diukur dengan termometer, setiap manusia memiliki suhu tubuh yang berbeda, walaupun suhu tubuhnya normal, tapi tetap saja ada perbedaan beberapa derajat. Suhu tubuh merupakan satuan yang mengukur keseimbangan panas yang diproduksi tubuh dengan panas yang dikeluarkan tubuh. Berikut ini kategori suhu tubuh manusia menurut usia yang diteliti oleh Applied Medical Infomatics pada tahun 1996 [7] :

Tabel 2. Suhu Tubuh Normal Berdasarkan Usia

\begin{tabular}{|c|c|}
\hline Usia & Temperatur $\left({ }^{\circ} \mathrm{C}\right)$ \\
\hline 0-3 bulan & 37,4 \\
\hline 3-6 bulan & 37,5 \\
\hline 6 bulan -1 tahun & 37,6 \\
\hline 1-3 tahun & 37,2 \\
\hline 3-5 tahun & 37 \\
\hline 5-9 tahun & 36,8 \\
\hline 9-13 tahun & 36,7 \\
\hline$>13$ tahun & $36,6-37,3$ \\
\hline
\end{tabular}

\section{PEMBAHASAN}

Pada penelitian kali ini, digunakan dua variabel untuk menyatakan status kesehatan tubuh seseorang, yaitu usia dan suhu tubuh.Variabel usia terbagi ke dalam empat himpunan fuzzy, yaitu : anak-anak, remaja, dewasa, dan tua, sedangkan variabel suhu tubuh terbagi ke dalam tiga himpunan fuzzy, yaitu : dingin, normal dan panas. Data keluaran dari penelitian ini merupakan pernyataan bahwa seseorang dinyatakan kurang sehat, sehat atau tidak sehat.

Usia dan suhu tubuh memiliki hubungan yang sangat erat. Setelah membaca dari berbagai sumber penelitian yang ada, maka pada penelitian kali ini, penulis berasumsi bahwa hubungan antara usia dan suhu tubuh dapat dituliskan seperti berikut ini :

Tabel 3. Hubungan Antara Usia dan Suhu Tubuh

\begin{tabular}{|c|c|c|}
\hline Himpunan & Usia & Suhu Tubuh Normal \\
\hline Anak-anak & $\mathrm{x} \leq 11$ & 37,0 \\
\hline Remaja & $12-25$ & 36,7 \\
\hline Dewasa & $26-45$ & 36,4 \\
\hline Tua & $\mathrm{x} \geq 46$ & 36,2 \\
\hline
\end{tabular}

Hubungan usia dan suhu tubuh yang telah diasumsikan sebelumnya akan digunakan sebagai acuan dalam penelitian ini, selain itu penulis juga merasa perlu menentukan acuan status kesehatan. Berikut ini asumsi untuk status kesehatan :

\begin{tabular}{|c|c|}
\multicolumn{2}{|c}{ Tabel 4. Status Kesehatan } \\
\hline Himpunan & Status Kesehatan \\
\hline Sehat & $\mathrm{z} \geq 0,6$ \\
\hline Kurang Sehat & $0,3 \leq \mathrm{z} \leq 0,5$ \\
\hline Tidak Sehat & $\mathrm{z} \leq 0,2$ \\
\hline
\end{tabular}




\section{A. Fuzzifikasi}

Proses fuzzifikasi pada penelitian ini dilakukan terhadap tiga variabel yang ada yaitu usia, suhu tubuh dan status kesehatan.

1) Fuzzifikasi Usia

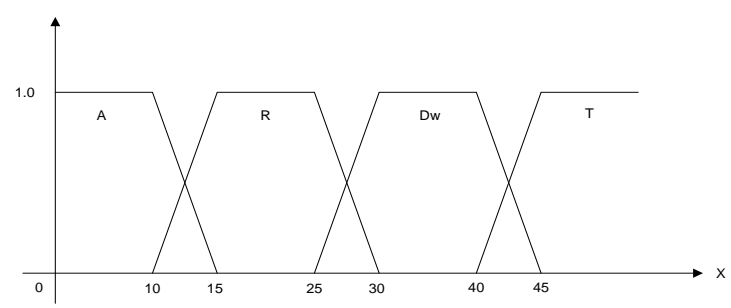

Gambar 2. Fuzzifikasi Usia

Fungsi Keanggotaan :

$$
\begin{aligned}
& \mu_{A}=\left\{\begin{array}{cc}
0 & x \geq 15 \\
\frac{15-x}{15-10} & 10 \leq x \leq 15 \\
1 & x \leq 10
\end{array}\right. \\
& \mu_{R}=\left\{\begin{array}{cc}
0 & x \leq 10 ; x \geq 30 \\
\frac{x-10}{15-10} & 10 \leq x \leq 15 \\
\frac{30-x}{30-25} & 25 \leq x \leq 30 \\
1 & 15 \leq x \leq 25
\end{array}\right. \\
& \mu_{D w}=\left\{\begin{array}{cc}
0 & x \leq 25 ; x \geq 45 \\
\frac{x-25}{30-25} & 25 \leq x \leq 30 \\
\frac{45-x}{45-40} & 40 \leq x \leq 45 \\
1 & 30 \leq x \leq 40
\end{array}\right. \\
& \mu_{T}=\left\{\begin{array}{cc}
0 & x \leq 40 \\
\frac{x-40}{45-40} & 40 \leq x \leq 45 \\
1 & x \geq 45
\end{array}\right.
\end{aligned}
$$

\section{2) Fuzzifikasi Suhu Tubuh}

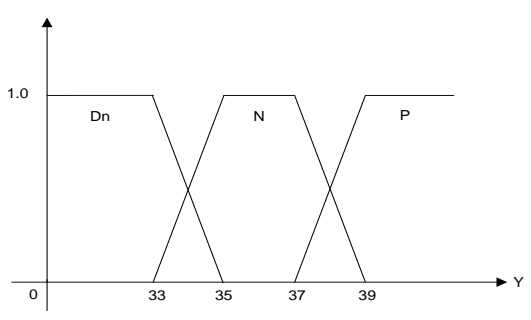

Gambar 3. Fuzzifikasi Suhu Tubuh

Fungsi Keanggotaan :

$$
\begin{aligned}
& \mu_{D n}=\left\{\begin{array}{cc}
0 & y \geq 35 \\
\frac{35-y}{35-33} & 33 \leq y \leq 35 \\
1 & y \leq 33
\end{array}\right. \\
& \mu_{N}=\left\{\begin{array}{cc}
0 & y \leq 33 ; y \geq 39 \\
\frac{y-33}{35-33} & 33 \leq y \leq 35 \\
\frac{39-y}{39-37} & 37 \leq y \leq 39 \\
1 & 35 \leq y \leq 37
\end{array}\right. \\
& \mu_{P}=\left\{\begin{array}{cc}
0 & y \leq 37 \\
\frac{y-37}{39-37} & 37 \leq y \leq 39 \\
1 & y \geq 39
\end{array}\right.
\end{aligned}
$$

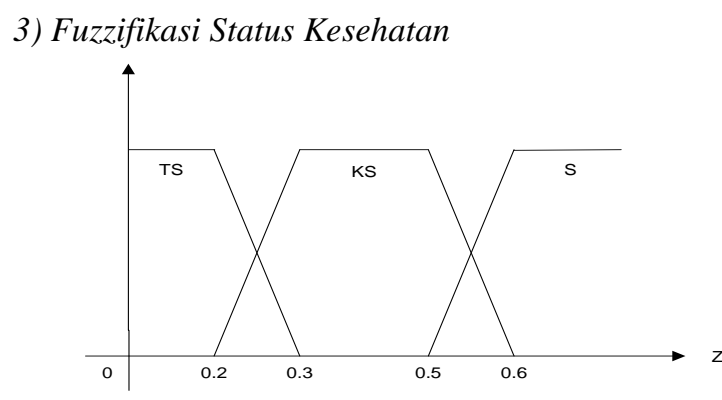

Gambar 4. Fuzzifikasi Status Kesehatan

Fungsi Keanggotaan :

$$
\mu_{\mathrm{TS}}=\left\{\begin{array}{cc}
0 & \mathrm{z} \geq 0,3 \\
\frac{0,3-\mathrm{z}}{0,3-0,2} & 0,2 \leq \mathrm{z} \leq 0,3
\end{array}\right.
$$




$$
\begin{gathered}
\mu_{\mathrm{KS}}=\left\{\begin{array}{cc}
1 & \mathrm{z} \leq 0,2 \\
0 & \mathrm{z} \leq 0,2 ; \mathrm{z} \geq 0,6 \\
\frac{\mathrm{z}-0,2}{0,3-0,2} & 0,2 \leq \mathrm{z} \leq 0,3 \\
\frac{0,6-\mathrm{z}}{0,6-0,5} & 0,5 \leq \mathrm{z} \leq 0,6 \\
1 & 0,3 \leq \mathrm{z} \leq 0,5
\end{array}\right. \\
\mu_{\mathrm{S}}=\left\{\begin{array}{cc}
0 & \mathrm{z} \leq 0,5 \\
\frac{\mathrm{z}-0,5}{0,6-0,5} & 0,5 \leq \mathrm{z} \leq 0,6 \\
1 & \mathrm{z} \geq 0,6
\end{array}\right.
\end{gathered}
$$

\section{B. Inferensi}

Pada proses inferensi, ditentukan beberapa aturan yang

akan digunakan untuk menarik kesimpulan. Berikut ini beberapa aturan yang ditentukan pada penelitian kali ini

[R1] Jika usia "anak-anak" dan suhu tubuh "dingin", maka

status kesehatan "kurang sehat".

[R2] Jika usia "anak-anak" dan suhu tubuh "normal", maka

status kesehatan "sehat".

[R3] Jika usia "anak-anak" dan suhu tubuh "panas", maka status kesehatan "tidak sehat".

[R4] Jika usia "remaja" dan suhu tubuh "dingin", maka status kesehatan "kurang sehat".

[R5] Jika usia "remaja" dan suhu tubuh "normal", maka status kesehatan "sehat".

[R6] Jika usia "remaja" dan suhu tubuh "panas", maka status kesehatan "tidak sehat".

[R7] Jika usia "dewasa" dan suhu tubuh "dingin", maka

status kesehatan "kurang sehat".

[R8] Jika usia "dewasa" dan suhu tubuh "normal", maka

status kesehatan "sehat".

[R9] Jika usia "dewasa" dan suhu tubuh "panas", maka status kesehatan "tidak sehat".

[R10] Jika usia "tua" dan suhu tubuh "dingin", maka status

kesehatan "kurang sehat".

[R11] Jika usia "tua" dan suhu tubuh "normal", maka status kesehatan "sehat".

[R12] Jika usia "tua" dan suhu tubuh "panas", maka status

kesehatan "tidak sehat".

\section{Aplikasi Masalah ke Aturan}

Sebagai contoh, ada permasalahan menentukan status

kesehatan seseorang yang berumur 12 tahun, dengan suhu tubuh $36^{\circ} \mathrm{C}$, dari masalah ini nantinya akan ditemukan solusi berupa pernyataan, apakah orang tersebut kurang sehat, sehat atau bahkan tidak sehat. Ada beberapa tahapan mencari solusi dari permasalah yang telah dipaparkan sebelumnya. Hal pertama yang dilakukan adalah menghitung fungsi keanggotaan masing-masing variabel :

$$
\begin{array}{ll}
\mu_{\mathrm{A}}=\frac{15-12}{15-10}=\frac{3}{5}=0,6 & \mu_{\mathrm{Dn}}=0 \\
\mu_{\mathrm{R}}=\frac{12-10}{15-10}=\frac{2}{5}=0,4 & \mu_{\mathrm{N}}=1 \\
\mu_{\mathrm{Dw}}=0 & \mu_{\mathrm{P}}=0 \\
\mu_{\mathrm{T}}=0 &
\end{array}
$$

Hal kedua yang dilakukan adalah mengaplikasikan aturan-aturan yang ada untuk menarik kesimpulan, dimana akan diperoleh $\alpha_{\text {-predikat }}$ dan nilai z :

[R1] Jika usia "anak-anak" dan suhu tubuh "dingin", maka

status kesehatan "kurang sehat".

$$
\begin{aligned}
& \alpha_{\text {-predikat 1 }}=\mu_{\mathrm{A}} \cap \mu_{\mathrm{Dn}} \\
& =\min (0,6 ; 0)=0 \\
& \mu_{\mathrm{KS}}=\frac{\mathrm{z}-0,2}{0,3-0,2} \quad \mu_{\mathrm{KS}}=\frac{0,6-z}{0,6-0,5} \\
& 0=\frac{\mathrm{z}-0,2}{0,1} \quad 0=\frac{0,6-\mathrm{z}}{0,1} \\
& \mathrm{z}-0,2=0 \quad 0,6-\mathrm{z}=0 \\
& \begin{array}{ll}
\mathrm{z}=0,2 & \mathrm{Z}=0,6
\end{array} \\
& \mathrm{z}_{1}=\min (0,2 ; 0,6)=0,2
\end{aligned}
$$

[R2] Jika usia "anak-anak" dan suhu tubuh "normal", maka status kesehatan "sehat".

$$
\begin{aligned}
\alpha_{\text {-predikat 2 }} & =\mu_{\mathrm{A}} \cap \mu_{\mathrm{N}} \\
& =\min (0,6 ; 1)=0,6
\end{aligned}
$$




$$
\begin{aligned}
\mu_{\mathrm{S}} & =\frac{\mathrm{z}-0,5}{0,6-0,5} \\
0,6 & =\frac{\mathrm{z}-0,5}{0,1} \\
\mathrm{z}-0,5 & =0,06 \\
\mathrm{z}_{2} & =0,56
\end{aligned}
$$

[R3] Jika usia "anak-anak" dan suhu tubuh "panas", maka

status kesehatan "tidak sehat".

$$
\begin{aligned}
\alpha_{\text {-predikat } 3} & =\mu_{\mathrm{A}} \cap \mu_{\mathrm{P}} \\
& =\min (0,6 ; 0)=0 \\
\mu_{\mathrm{TS}} & =\frac{0,3-\mathrm{z}}{0,3-0,2} \\
0 & =\frac{0,3-\mathrm{z}}{0,1} \\
0,3-\mathrm{z} & =0 \\
\mathrm{z}_{3} & =0,3
\end{aligned}
$$

[R4] Jika usia "remaja" dan suhu tubuh "dingin", maka status kesehatan "kurang sehat".

$$
\begin{aligned}
& \alpha_{\text {-predikat } 4}=\mu_{\mathrm{R}} \cap \mu_{\mathrm{Dn}} \\
& =\min (0,4 ; 0)=0 \\
& \mu_{\mathrm{KS}}=\frac{\mathrm{z}-0,2}{0,3-0,2} \quad \mu_{\mathrm{KS}}=\frac{0,6-z}{0,6-0,5} \\
& 0=\frac{\mathrm{z}-0,2}{0,1} \quad 0=\frac{0,6-\mathrm{z}}{0,1} \\
& \mathrm{z}-0,2=0 \quad 0,6-\mathrm{z}=0
\end{aligned}
$$

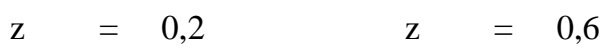

$$
\begin{aligned}
& \mathrm{z}_{4}=\min (0,2 ; 0,6)=0,2
\end{aligned}
$$

[R5] Jika usia "remaja" dan suhu tubuh "normal", maka

status kesehatan "sehat".

$$
\begin{aligned}
\alpha_{\text {-predikat } 5} & =\mu_{\mathrm{R}} \cap \mu_{\mathrm{N}} \\
& =\min (0,4 ; 1)=0,4 \\
\mu_{\mathrm{S}} & =\frac{\mathrm{z}-0,5}{0,6-0,5} \\
0,4 & =\frac{\mathrm{z}-0,5}{0,1} \\
\mathrm{z}-0,5 & =0,04 \\
\mathrm{z}_{5} & =0,54
\end{aligned}
$$

[R6] Jika usia "remaja" dan suhu tubuh "panas", maka status kesehatan "tidak sehat".

$$
\begin{aligned}
\alpha_{\text {-predikat } 6} & =\mu_{\mathrm{R}} \cap \mu_{\mathrm{P}} \\
& =\min (0,4 ; 0)=0 \\
\mu_{\mathrm{TS}} & =\frac{0,3-\mathrm{z}}{0,3-0,2} \\
0 & =\frac{0,3-\mathrm{z}}{0,1} \\
0,3-\mathrm{z} & =0 \\
\mathrm{z}_{6} & =0,3
\end{aligned}
$$

[R7] Jika usia "dewasa" dan suhu tubuh "dingin", maka status kesehatan "kurang sehat".

$$
\begin{array}{rlrl}
\alpha_{\text {-predikat 7 }} & =\mu_{\mathrm{D}} \cap \mu_{\mathrm{Dn}} & & \\
& =\min (0 ; 0)=0 & & \\
\mu_{\mathrm{KS}} & =\frac{\mathrm{z}-0,2}{0,3-0,2} & \mu_{\mathrm{KS}} & =\frac{0,6-\mathrm{z}}{0,6-0,5} \\
0 & =\frac{\mathrm{z}-0,2}{0,1} & 0 & =\frac{0,6-\mathrm{z}}{0,1} \\
\mathrm{z}-0,2 & =0 & 0,6-\mathrm{z} & =0 \\
\mathrm{z} & =0,2 & \mathrm{z} & =0,6
\end{array}
$$$$
\mathrm{z}_{7}=\min (0,2 ; 0,6)=0,2
$$

[R8] Jika usia "dewasa" dan suhu tubuh "normal", maka status kesehatan "sehat".

$$
\begin{aligned}
\alpha_{\text {-predikat } 8} & =\mu_{\mathrm{D}} \cap \mu_{\mathrm{N}} \\
& =\min (0 ; 1)=0 \\
\mu_{\mathrm{S}} & =\frac{\mathrm{z}-0,5}{0,6-0,5} \\
0 & =\frac{\mathrm{z}-0,5}{0,1} \\
\mathrm{z}-0,5 & =0 \\
\mathrm{z}_{8} & =0,5
\end{aligned}
$$

[R9] Jika usia "dewasa" dan suhu tubuh "panas", maka status kesehatan "tidak sehat".

$$
\begin{aligned}
\alpha_{\text {-predikat } 9} & =\mu_{\mathrm{D}} \cap \mu_{\mathrm{P}} \\
& =\min (0 ; 0)=0 \\
\mu_{\mathrm{TS}} & =\frac{0,3-\mathrm{z}}{0,3-0,2} \\
0 & =\frac{0,3-\mathrm{z}}{0,1} \\
0,3-\mathrm{z} & =0
\end{aligned}
$$




$$
\mathrm{z}_{9} \quad=0,3
$$

[R10] Jika usia "tua" dan suhu tubuh "dingin", maka status

kesehatan "kurang sehat".

$$
\begin{aligned}
& \alpha_{\text {-predikat 10 }}=\mu_{\mathrm{T}} \cap \mu_{\mathrm{Dn}} \\
& =\min (0 ; 0)=0 \\
& \mu_{\mathrm{KS}}=\frac{\mathrm{z}-0,2}{0,3-0,2} \quad \mu_{\mathrm{KS}}=\frac{0,6-z}{0,6-0,5} \\
& 0=\frac{\mathrm{z}-0,2}{0,1} \\
& 0=\frac{0,6-\mathrm{z}}{0,1} \\
& \mathrm{z}-0,2=0 \\
& \mathrm{z}=0,2 \\
& 0,6-\mathrm{z}=0 \\
& \mathrm{z}=0,6 \\
& \mathrm{z}_{10}=\min (0,2 ; 0,6)=0,2
\end{aligned}
$$

[R11] Jika usia "tua" dan suhu tubuh "normal”, maka status kesehatan "sehat".

$$
\begin{aligned}
\alpha_{\text {-predikat 11 }} & =\mu_{\mathrm{T}} \cap \mu_{\mathrm{N}} \\
& =\min (0 ; 1)=0 \\
\mu_{\mathrm{S}} \quad & =\frac{\mathrm{z}-0,5}{0,6-0,5} \\
0 & =\frac{\mathrm{z}-0,5}{0,1} \\
\mathrm{z}-0,5 & =0 \\
\mathrm{z}_{11} & =0,5
\end{aligned}
$$

[R12] Jika usia "tua" dan suhu tubuh "panas", maka status kesehatan "tidak sehat".

$$
\begin{aligned}
\alpha_{\text {predikat 12 }} & =\mu_{\mathrm{T}} \cap \mu_{\mathrm{P}} \\
& =\min (0 ; 0)=0 \\
\mu_{\mathrm{TS}} & =\frac{0,3-\mathrm{z}}{0,3-0,2} \\
0 & =\frac{0,3-\mathrm{z}}{0,1} \\
0,3-\mathrm{z} & =0 \\
\mathrm{Z}_{12} & =0,3
\end{aligned}
$$

\subsection{Defuzzifikasi}

Proses defuzzifikasi dari masalah yang dipaparkan sebelumnya adalah dengan menentukan nilai Z. Berikut ini perhitungan nilai $\mathrm{Z}$ :

$$
\begin{aligned}
\mathrm{Z} & =\frac{a_{\text {pred } 1} * \mathrm{Z} 1+a_{\text {pred } 2} * \mathrm{Z} 2+a_{\text {pred } 3} * \mathrm{Z} 3+\cdots+a_{\text {pred } 12} * \mathrm{Z} 12}{a_{\text {pred } 1}+a_{\text {pred } 2}+a_{\text {pred } 3}+\cdots+a_{\text {pred } 12}} \\
& =\frac{0+0,336+0+0+0,216+0+0+0+0+0+0+0}{0+0,6+0+0+0,4+0+0+0+0+0+0+0}=\frac{0,552}{1}=0,552
\end{aligned}
$$

Dari hasil defuzzifikasi, diperoleh nilai $\mathrm{Z}=0,552$, ini membuktikan bahwa anak yang berumur 12 tahun dan memiliki suhu tubuh $36^{\circ} \mathrm{C}$ tersebut masuk ke dalam kategori "kurang sehat".

\section{KESIMPULAN}

Berikut ini adalah kesimpulan terhadap pembahasan metode fuzzy Tsukamoto dalam menyelesaikan permasalahan menentukan status kesehatan tubuh seseorang :

1. Metode fuzzy Tsukamoto membuktikan bahwa status kesehatan tubuh seseorang sangat dipengaruhi oleh usia dan suhu tubuh. Perbedaan usia membuat suhu tubuh setiap manusia berbeda, sehingga kategori status kesehatan manusia tersebut juga berbeda-beda.

2. Untuk menyelesaikan permasalahan pada penelitian ini, metode fuzzy Tsukamoto menggunakan proses fuzzifikasi, inferensi, aplikasi masalah ke aturan serta defuzzifikasi, dan memperoleh hasil yang mendekati fakta atau kenyataan yang ada.

\section{REFERENSI}

[1] Budi Rackman, Muklis., Ardianto. 2013. Sistem Pakar untuk Diagnosis Penyakit pada Tanaman Teh dengan Metode Fuzzy Logic Berbasis Android. Skripsi. Indonesia : STMIK MDP.

[2] Istraniady., Andrian, Priko. Analisis Perbandingan Metode Fuzzy Tsukamoto dan Metode Fuzzy Mamdani pada Perbandingan Harga Sepeda Motor Bekas. Jurnal. STMIK GI MDP.

[3] J Klir, George., Yuan, Bo. 1995. Fuzzy Sets and Fuzzy Logic, Theory and Application, Prentice Hall.

[4] Kantardzic, Mehmed. 2003. Data Mining Concepts, Models, Methods, and Algorithms. IEEE Press.

[5] Kusuma Dewi, S., Purnomo, Hari. 2004. Aplikasi Logika Fuzzy untuk Pendukung Keputusan. Graha Ilmu : Yogyakarta.

[6] Marinus H, Yoakim., Kusumastuti, N., Irawan, Beni. 2014. Pengendalian Kecepatan Kendaraaan Roda Empat dengan Menggunakan Fuzzy Inference System Metode Mamdani. Jurnal. Volume 03, No.1(2014), hal 39-46.

[7] http://drlusia.blogspot.com/2011/04/demam.html (Diakses pada tanggal 18 Maret 2015)

[8] http://ilmu-kesehatan masyarakat.blogspot.com/2012/05/ kategori-umur.html (Diakses pada tanggal 19 Maret 2015) 